\title{
A comparative study on genetic characteristics of two new varieties of Pelodiscus sinensis and their hybrid
}

\author{
H.Q. Zhang ${ }^{1,2,3}$, X.J. Xu' ${ }^{2}$, Z.Y. He ${ }^{2}$, J.Z. Shao ${ }^{1}$, X.H. Zhang ${ }^{2}$, Q.H. Meng ${ }^{2}$ \\ and F.Y. Huang ${ }^{2}$ \\ ${ }^{1}$ College of Life Sciences, Zhejiang University, Hangzhou, Zhejiang, China \\ ${ }^{2}$ Zhejiang Fisheries Technical Extension Center, Hangzhou, Zhejiang, China \\ ${ }^{3}$ Zhejiang Institute of Freshwater Fisheries, Huzhou, Zhejiang, China \\ Corresponding author: H.Q. Zhang \\ E-mail: zmk407@126.com
}

Genet. Mol. Res. 16 (3): gmr16039148

Received September 2, 2016

Accepted August 15, 2017

Published September 21, 2017

DOI http://dx.doi.org/10.4238/gmr16039148

Copyright (C) 2017 The Authors. This is an open-access article distributed under the terms of the Creative Commons Attribution ShareAlike (CC BY-SA) 4.0 License.

\begin{abstract}
Chinese soft-shelled turtle Pelodiscus sinensis has been an important aquaculture species in Southeast Asian countries. To breed a new variety of soft-shelled turtle with excellent properties and to evaluate the effect of hybridization of two turtle strains with a highly different trait phenotype, inheritance, microsatellite loci, and transcriptome analysis were studied in the hybrid turtles and their parents of $P$. sinensis Japanese strain and Qingxi black turtle. The genotypic characteristics and economic trait of the hybrid turtles were analyzed and compared to the two parents, showing significant growth vigor. The chromosome number of the hybrid turtle was diploid $(2 \mathrm{~N}=66)$. The karyotype formulae were $8 \mathrm{~m}+10 \mathrm{sm}+26 \mathrm{t}+22 \mathrm{mc}$, with little differences between the two parents. Genotypic segregations of 241 microsatellite loci were screened in 3 populations including 90 species and showed that the specific allele numbers and polymorphic fragments increased in hybrid turtles indicating genetic diversity increased by hybridization. The liver transcriptome analysis of the
\end{abstract}


hybrids and two parents showed similar distribution abundance in the parental and hybrid groups, but the transcripts with high abundance appeared in the hybrid group. There were 274 significant differentially expressed transcripts in the hybrid group compared to the two parental groups, among them 7 differentially expressed genes indicating superparent expression, and only 2 genes showing low-parent expression. In the differentially expressed genes, expression changes were mainly contributed to regulatory region changes rather than coding region sequences. These results would be important for facilitating successful breeding strategies by hybridization in $P$. sinensis.

Key words: Pelodiscus sinensis; Qingxi black turtle; Transcriptome; Chinese soft-shelled turtle; Hybridization; Morphological variation

\section{INTRODUCTION}

Chinese soft-shelled turtle Pelodiscus sinensis is one of freshwater turtle species of Reptilia belonging to the Family Trionychidae (Aleherr and Freyer, 2000; Bonin et al., 2006), which is widely distributed in China (including Taiwan), Japan, Korea, Vietnam, and other Southeast Asian countries (Zhang et al., 1998). Due to its high nutritional and medicinal values, the soft-shelled turtle culture has developed rapidly and become one of the important aquaculture industry in China, with the production of 355,000 tons in 2014 (Bureau of Fisheries, 2015) and the total value of over 250 million (He et al., 2015). The soft-shelled turtle culture gives an approach to high economic aquaculture. A farmer who runs a small-scale farm with stocking 30,000-50,000 turtles, on average, earns 15 thousand US dollars and there are more than 100 thousand farmers who take the culture of the main earning income at present (Shao, 2013). The emergence of soft-shelled turtle culture diversifies the lists of important culture species in China and offers the farmers the important practice for their livelihood improvement.

High-quality and sufficient fingerlings are the important factor for the sustainable development of soft-shelled turtle industry. Although artificial propagation was started to meet the requirements in the 1990s, the shortage of fingerling supply did not substantially improve. Due to the shortage of the domestic fingerlings, farmers usually imported the fertilized eggs in large scales mainly from the Taiwan region and some Southeast Asian countries to meet the farming needs in the middle of 1990s. Although the imported eggs met the need of the culture industry, it carried diseases, and its growth became slowly (Wu and Zeng, 2007). Therefore, the selecting and breeding of superior species have highly aroused the attention of the governments, culturist, and breeding workers; the new varieties with fast growth rate, good flavor, and strong disease-resistance become very necessary to be produced.

Crossbreeding has been well applied in the $P$. sinensis aquaculture as the classical breeding way. The hybrids $\left(\mathrm{F}_{1}\right)$ of $P$. sinensis and Truogx sinensis have the characteristics of big size, good color, high output, strong ability of reproduction, and disease-resistant and produced more profits than the parent $P$. sinensis (Shi and Li, 2005). According to the comparison among the offspring of Chinese soft-shelled turtle in Yellow River population, Japanese strain and their hybrids $\left(\mathrm{F}_{1}\right)$, the growth traits of hybrids $\left(\mathrm{F}_{1}\right)$ are the parents of the Yellow River population and Japanese strain, but in some vitally economic traits of weight, height, width, hybrids $\left(\mathrm{F}_{1}\right)$ is apparently better than the parents (Jia, 2007; Wang et al., 2009).

Genetics and Molecular Research 16 (3): gmr16039148 
Besides, the contents in flavored amino acid and fatty acid of hybrids are higher than those of the parents, which indicates that hybrids $\left(\mathrm{F}_{1}\right)$ have the advantage on the nutritive qualities and flavor (Jia, 2007; Wang et al., 2009). From the growth comparison of Chinese soft-shelled turtle different geographical populations and the hybrids among the Dongting Lake population and Yellow River population, the growth traits of hybrids are better than self-bred turtles of Dongting Lake population and Yellow River population (Liu et al., 2012). A germplasm bank for soft-shelled turtle was established with material collected from different geographical locations that included Taihu populations, Yellow River populations, Japanese strains, Qingxi black turtle, and other strains (He, 2014). As the morphological characteristics of some populations are similar, some rapid and accurate molecular differentiation methods such as RFLP-PCR (Zhang et al., 2015a) and SNP-HRM (Zhang et al., 2015b) were established to assist identification of the different populations/strains. Based on the characteristics of $P$. sinensis germplasm resources, Qingxi black turtle and Japanese strain were cultivated and authorized the new breed certificated by Ministry of Agriculture of the China (Zhang et al., 2011). P. sinensis Japanese strain grows fast and has strong resistance to diseases, but is weaker in the flavor and price than the local native species. Qingxi black turtle has the stable inheritance of pitch-black body color and good flavor, while its growth rate is not as fast as the Japanese strain (Zhang et al., 2008; Xue et al., 2009). Thus, the objective of this study was to combine the advantages of the two new varieties of Qingxi black turtle and the Japanese strain of $P$. sinensis and evaluate the effect of hybridization of two turtle strains with a highly different trait phenotype.

\section{MATERIAL AND METHODS}

\section{Parents}

Female parents with original size over $1 \mathrm{~kg}$ were $P$. sinensis Japanese strain, which was bred after the 5th generation of selection by the Aquatic Products Breeding Center of Zhejiang Province and Hangzhou Xiaoshan Tianfu Bio-Tech Co., Ltd.

Male parents with original size over $0.75 \mathrm{~kg}$ were Qingxi black turtle, which was selected as the new breed from 5th-generation groups by the Aquatic Products Breeding Center of Zhejiang Province and Zhejiang Qingxi Turtle Industry Co., Ltd.

\section{Hybridization}

The turtles were stocked in pond outdoor with the area of $4000 \mathrm{~m}^{2}$. A fence to escape of $50-60 \mathrm{~cm}$ in height with a sand bed of 30-40 cm thickness with top shelter as spawning site was set. The stock density was 30,000 individuals/ha, and the ratio of female to male was 5-7:1. The turtles were disinfected with $100 \times 10^{-6}$ potassium permanganate solution before stocking. The first mating time was from October to November when the water temperature was below $25^{\circ} \mathrm{C}$.

\section{Egg collecting, hatching, and juvenile turtle cultivating}

After careful nurturing, the females laid eggs in the next year from May 10 to August 25 , with the total number of 55-110 eggs/individual. The fertilized eggs were collected on the following day, and transferred to trays and kept in a hatching room maintained at $30^{\circ}-32^{\circ} \mathrm{C}$

Genetics and Molecular Research 16 (3): gmr16039148 
and relative humidity of $80-85 \%$. The humidity of sand was about $7-8 \%$, and the total hatching temperature was about $36^{\circ} \mathrm{C}$. To evaluate the performance of the hybrids and their parents, the hatched juvenile turtles were cultivated in special ponds after 2 days for temporary rearing according to the Chinese National Standard of GB/T26876-2011, which was widely adopted by researchers and recommended by the Ministry of Agriculture of China (Shen et al., 2011).

\section{Morphological, growth characteristics, and chromosome analysis}

Ninety turtles of female individuals of $P$. sinensis Japanese strain, male individuals of Qingxi black turtle and their hybrid adults were measured according to the uniform Chinese National Standard of GB 21044-2007 (Zhang et al., 2007). The measurable character indexes were analyzed including carapace length, carapace width, back apron width, snout length, protuberant snout length, protuberant snout width, interorbital width, as well as the statistical analysis of the proportion between each index and carapace length. The body color was recorded and analyzed by a Camera.

The differences in growth characteristics between a young hybrid turtle and the natural population of Japanese strain and Qingxi black turtle were studied using different fluorescent labeling technique to eliminate the deviation caused by environmental factors $(\mathrm{Xu}$ et al., 2012). One hundred individuals of each turtle were cultivated in the same pool, and three parallels were done. Chromosome and karyotype formula were analyzed according to the Chinese National Standard of GB 21044-2007 (Zhang et al., 2007).

\section{Microsatellite analysis}

Nine primers were designed and synthesized for PCR amplification according to reports (Botstein et al., 1980; Que et al., 2007; Zhu et al., 2012; Meng et al., 2013) (Table 1). Amplification was performed in $10-\mu \mathrm{L}$ reaction mixtures containing PCR buffer with $5 \mu \mathrm{L}$ TaKaRa Mix, $1 \mu \mathrm{L}$ of each primer, $1 \mu \mathrm{L}$ DNA template, and $3 \mu \mathrm{L} \mathrm{ddH_{2 }}$ O. The PCR mixture was performed on ABI Veriti PCR. PCR amplified products were analyzed using the QIAxcel Automatic Acid Analysis. Analysis data using the POPGEN32 program were recorded as the number of alleles, an effective number of alleles $\left(N_{\mathrm{E}}\right)$, observed heterozygosity $\left(H_{\mathrm{O}}\right)$, expected heterozygosity $\left(H_{\mathrm{E}}\right)$, and genetic distance, genetic similarity coefficient, and other parameters. Polymorphism information content (PIC) was calculated with CALC v. 0.6.

\begin{tabular}{|c|c|c|c|c|c|c|}
\hline Primer & Forward primer sequences & Reverse primer sequences & Repeating unit & Fragment size & $\operatorname{Tm}\left({ }^{\circ} \mathrm{C}\right)$ & GenBank accession No. \\
\hline SSR01 & AGGCCAGAAGGGACCATTTA & \begin{tabular}{|l} 
TGGTCGATCATTTTGCTGTG \\
\end{tabular} & $(\mathrm{GT})_{18}$ & $215-246$ & 60 & DQ371907 \\
\hline SSR02 & \begin{tabular}{|l|l|} 
CATGGTCTAGGCAGTGCTGA \\
\end{tabular} & GAGAGAACAGCCTCGCTGA & $(\mathrm{CA})_{9}$ & $121-125$ & 60 & DQ371911 \\
\hline SSR03 & \begin{tabular}{|l|l|} 
GCCACGTACTCGTGGTCAT \\
\end{tabular} & \begin{tabular}{|l|} 
GGAGGCTGTTTCACGACTG \\
\end{tabular} & (TG) 9 & $108-110$ & 58 & DQ371915 \\
\hline SSR04 & GCACCAGGAAAGAGTCAAGAA & CAGCCCGAGAACATCAGAAT & $(\mathrm{AC})_{8}$ & $123-125$ & 58 & DQ371916 \\
\hline SSR05 & CAACCCAACTCTGCAGACAC & GAATTGCATGGAAGGCAGAT & $(\mathrm{AC})_{16}$ & 153-169 & 62 & DQ371922 \\
\hline SSR06 & AAAGCAGGGGAGAGAACAGC & \begin{tabular}{|l|l} 
CATGGTCAGGCAGTGCTGA \\
\end{tabular} & $(\mathrm{GT})_{9}$ & $132-134$ & 62 & DQ371923 \\
\hline SSR07 & GCACCAGGAAAGAGTCAAGAA & CAGCCCGAGAACATCAGAAT & $(\mathrm{AC})_{8}$ & $123-125$ & 58 & DQ371924 \\
\hline SSR08 & ACGCAGGACCAAGAGTGAGG & TGTGCCACTCCCCGTATTGT & $(\mathrm{CA})_{10}$ & $145-151$ & 58 & DQ371917 \\
\hline SSR09 & AGTGAACCTTGCACATCCCAG & \begin{tabular}{|l} 
TCCAGTGAAGGTTCCAGACA \\
\end{tabular} & $(\mathrm{GT})_{10}$ & $161-185$ & 62 & DQ371914 \\
\hline
\end{tabular}

\section{Liver transcriptome analysis}

The liver of each of the 5 individuals was collected and used for transcription analysis. Total RNA was extracted using Trizol RNA kit (QIAGEN, Hilden, Germany). The

Genetics and Molecular Research 16 (3): gmr16039148 
concentration and purity of the total RNA were determined with Agilent Bioanalyzer (nucleic acid/protein analyzer) with $\left(\mathrm{OD}_{260} / \mathrm{OD}_{280}\right)$ greater than 2.0 , RNA $28 \mathrm{~S}: 18 \mathrm{~S} \geq 1, \mathrm{RIN} \geq 8$. RNA samples were saved in dry ice immediately and sent to the ILLUMINA Gene Company for mRNA sequencing (Wang et al., 2013). Clean reads were compared with mapped genomic sequence of $P$. sinensis by using Tophat v. 2.0.5 (Trapnell et al., 2009). Differentially expression levels were calculated with the formulae $\log 2$ ratio $(\mathrm{E} / \mathrm{C})$, where $\mathrm{E}$ is the $\mathrm{RPKM}$ of the gene in the experimental group, and C is the RPKM of the gene in the control group (Mortazavi et al., 2008). FDR of every differentially expressed gene was figured out as the algorithm of Benjamini and Yekutieli (2001). In this experimental analysis, we defined FDR $\leq 0.001$ and $\log 2$ ratio $\geq$ 1 as a significant difference in expression levels of the gene. The smaller the value of FDR, representing different multiples of the larger, more significant differences in gene expression. Gene Ontology (GO) function analysis and pathway KEGG analysis of differentially expressed genes were then analyzed (Ashburner et al., 2000; Kanehisa et al., 2012).

\section{RESULTS}

\section{Morphology characteristics}

Morphology characteristic parameters of $P$. sinensis Japanese strain, Qingxi black turtle, and their hybrids were shown in Table 2. Hybrids of $P$. sinensis Japanese strain and Qingxi black turtle had an elliptical body, grayish-black back, a hard bony covered notum, and abdomen. The epidermis had bulges, small warts, and longitudinal ridge, grayish-white abdomen, large patches of black, which gradually become shallower during growing. The body of $P$. sinensis Japanese strain had a black-green or black-gray back, and its abdomen was grayish white and had light green or light gray-brown spots. The juvenile Japanese strain turtle had a large triangular spot in the center of the abdomen, but the black spot gradually disappeared when the turtle grew. Qingxi black turtle had an ovoid carapace and arch humpback, and spines were visible. The epidermis had bulges, small warts, and longitudinal ridge. The back was black and covered dark black markings; the abdomen was gray-black with no blotches (Figure 1).

Table 2. Characteristic parameters of the Pelodiscus sinensis Japanese strain, the Qingxi black turtle, and their
hybrid.
\begin{tabular}{l|c|c|c|c|c|c}
\hline \multirow{2}{*}{ Item } & Standard of $P$. sinensis (GB 21044-2007) & Japanese strain & Qingxi black turtle & \multicolumn{3}{c}{ Hybrid turtle } \\
\cline { 2 - 7 } & Female & Male & Female & Male & Female & Male \\
\hline Carapace width/Carapace length & $0.840 \pm 0.037$ & $0.819 \pm 0.041$ & $0.865 \pm 0.023$ & $0.814 \pm 0.039$ & $0.834 \pm 0.019$ & $0.817 \pm 0.036$ \\
\hline Shell height/Carapace length & $0.267 \pm 0.061$ & $0.244 \pm 0.017$ & $0.324 \pm 0.012$ & $0.256 \pm 0.017$ & $0.316 \pm 0.029^{*}$ & $0.284 \pm 0.022$ \\
\hline Back apron width/Carapace length & $0.084 \pm 0.013$ & $0.091 \pm 0.011$ & $0.087 \pm 0.009$ & $0.092 \pm 0.008$ & $0.080 \pm 0.008$ & $0.079 \pm 0.013$ \\
\hline Snout legth/Carapace length & $0.084 \pm 0.009$ & $0.087 \pm 0.006$ & $0.089 \pm 0.008$ & $0.097 \pm 0.005$ & $0.097 \pm 0.008^{*}$ & $0.099 \pm 0.007^{*}$ \\
\hline Protuberant snout legth/Carapace length & $0.041 \pm 0.004$ & $0.043 \pm 0.006$ & $0.037 \pm 0.003$ & $0.045 \pm 0.006$ & $0.049 \pm 0.006^{*}$ & $0.045 \pm 0.006$ \\
\hline Protuberant snout width/Carapace length & $0.036 \pm 0.005$ & $0.035 \pm 0.010$ & $0.031 \pm 0.002$ & $0.036 \pm 0.005$ & $0.039 \pm 0.003$ & $0.037 \pm 0.004$ \\
\hline Interorbital distance/Carapace length & $0.032 \pm 0.005$ & $0.032 \pm 0.004$ & $0.029 \pm 0.002$ & $0.031 \pm 0.003$ & $0.032 \pm 0.002$ & $0.032 \pm 0.004$ \\
\hline$* P<0.05$. & & & & &
\end{tabular}

\section{Growth}

In immature stage, after 75 days of cultivation contrast test in the same pool, the growth rate of the juvenile hybrid was faster than P. sinensis Japanese strain, on average by

Genetics and Molecular Research 16 (3): gmr16039148 
15.89\%, and faster than Qingxi black turtle, on average by 30.85\% (Figure 2). However, in the immature stage, the growth rate of the juvenile hybrid was faster than $P$. sinensis Japanese strain on average by $14.5 \%$ and faster than Qingxi black turtle on average by $53.6 \%$ (Figure $3)$. The faster growth ratio of hybrid turtle obviously showed the super-parent phenomenon.

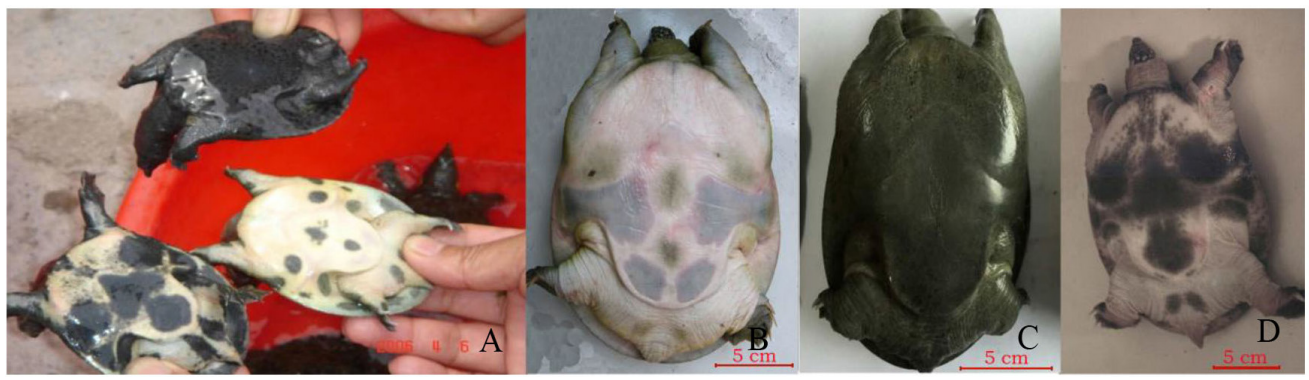

Figure 1. Comparison of abdomen color of the three kinds of Pelodiscus sinensis. A. Phenotype of young turtles; B. phenotype of adult turtles of the Japanese strain; C. Qingxi black turtle; and D. their hybrid.

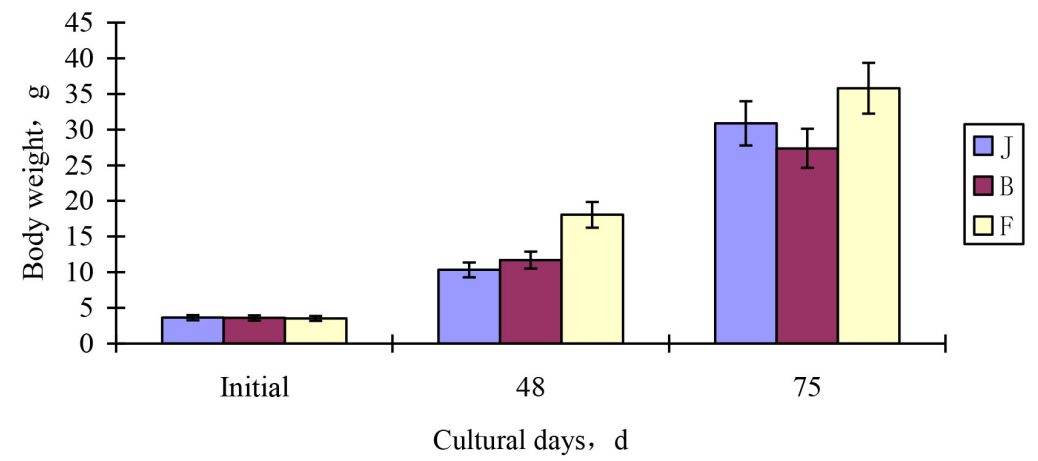

Figure 2. Growth of the hybrid turtle and its parents at an immature stage. J: Japanese strain, B: Qingxi black turtle, F: hybrid turtle. $* \mathrm{P}<0.05 ; * * \mathrm{P}<0.01$.

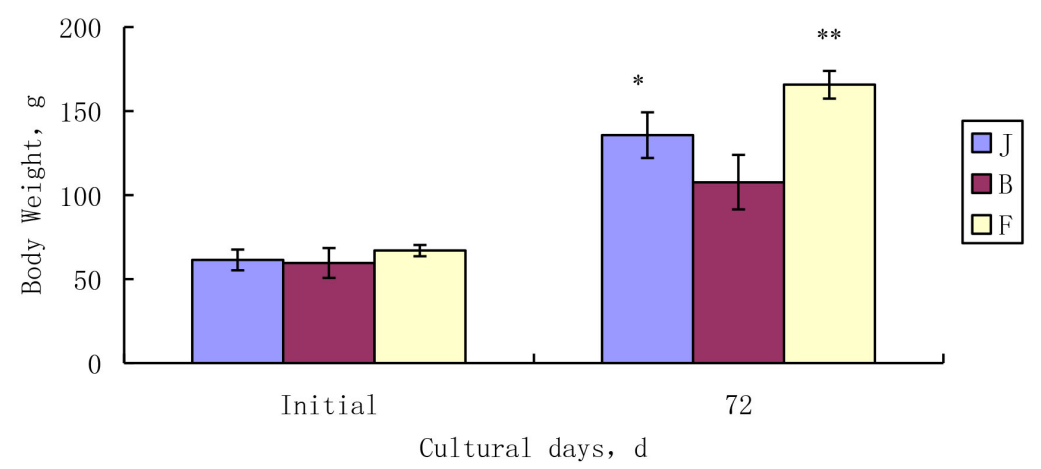

Figure 3. Growth of the hybrid turtle and its parents at a young stage. J: Japanese strain, B: Qingxi black turtle, F: hybrid turtle. ${ }^{*} \mathrm{P}<0.05 ;{ }^{*} \mathrm{P}<0.01$. 


\section{Chromosome and karyotype formula}

The number of chromosomes of the hybrid turtle was diploid, $2 \mathrm{~N}=66$. The karyotype formula was $8 \mathrm{~m}+10 \mathrm{sm}+26 \mathrm{t}+22 \mathrm{mc}$, while those of $P$. sinensis Japanese strain and Qingxi black turtle were $10 m+8 s m+22 t+26 m c$ and $10 m+14 s m+20 t+22 m c$, respectively (Figures 4,5 , and 6). There was no significant difference with parents in karyotype analysis.
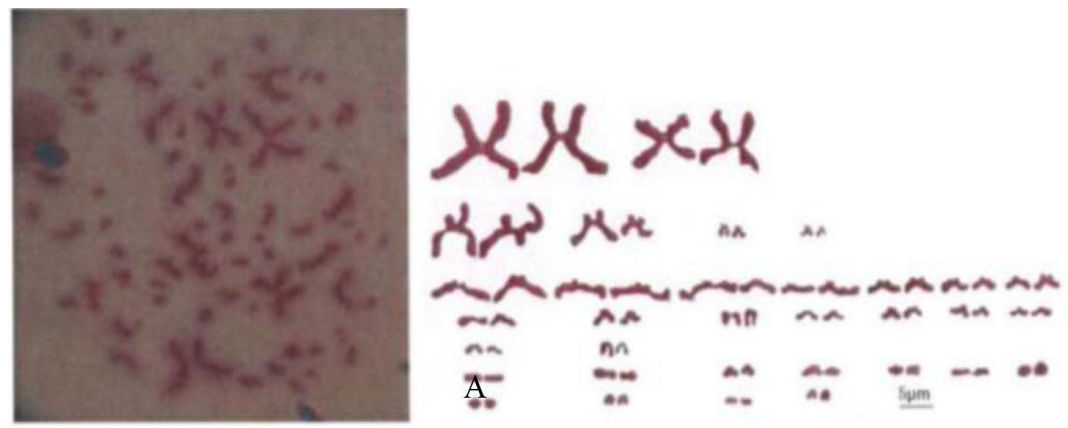

Figure 4. Chromosome analysis of the Pelodiscus sinensis Japanese strain. A. $2 \mathrm{~N}=66$. B. Karyotype formulae $=$ $10 \mathrm{~m}+8 \mathrm{sm}+22 \mathrm{t}+26 \mathrm{mc}$.
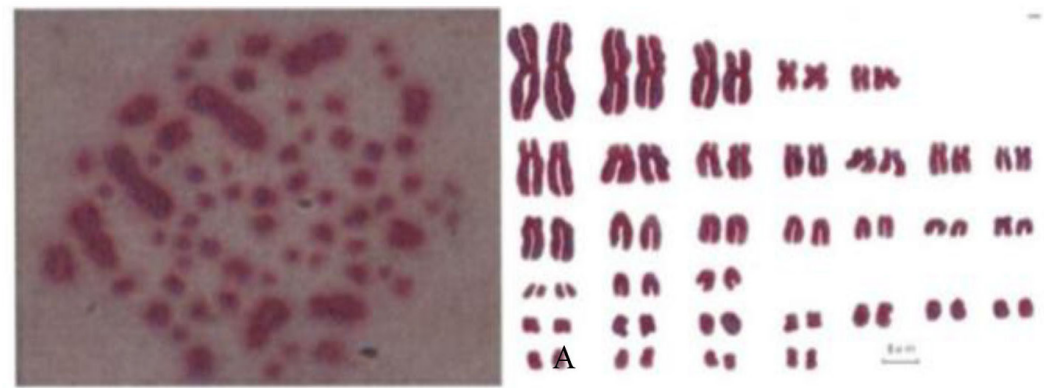

Figure 5. Chromosome analysis of the Qingxi black turtle. A. $2 \mathrm{~N}=66$. B. Karyotype formulae $=$ $10 \mathrm{~m}+14 \mathrm{sm}+20 \mathrm{t}+22 \mathrm{mc}$.
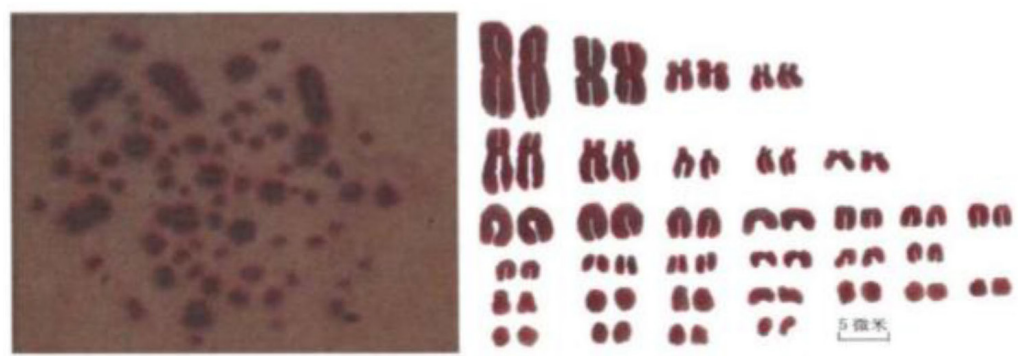

Figure 6. Chromosome analysis of the hybrid turtle of Pelodiscus sinensis Japanese strain and Qingxi black turtle. A. $2 \mathrm{~N}=66$. B. Karyotype formulae $=8 \mathrm{~m}+10 \mathrm{sm}+26 \mathrm{t}+22 \mathrm{mc}$. 


\section{Microsatellite genetic diversity}

Two hundred and forty-one microsatellite loci were screened in 3 populations by the 9 combinations of primers. Among the 241 microsatellite loci, the specific allele numbers reached 130; allele numbers ranged from 14.56 to 20.22 on average, and the specific allele numbers were distributed from 9.51 to 11.58 . The $H_{\mathrm{E}}$ of three populations ranged from 0.8436 to 0.9688 and reached 0.9218 on average, and $H_{\mathrm{O}}$ ranged from 0.1000 to 0.9222 and reached 0.5131 on average. Polymorphic fragments ranged from 0.8582 to 0.8953 (Table 3). Furthermore, the $H_{\mathrm{E}}$ of the hybrid turtle was 0.9186 , higher than 0.9046 of the Qingxi black turtle and 0.8869 of the $P$. sinensis Japanese strain, showing that hybridization of $P$. sinensis with different populations could enhance genetic diversity.

Table 3. Effective allele, heterozygosity, and PIC of the soft-shelled turtle at each locus assayed.

\begin{tabular}{l|c|c|c|c}
\hline Strain or primer & $N_{\mathrm{E}}$ & $H_{\mathrm{O}}$ & $H_{\mathrm{E}}$ & PIC \\
\hline $\mathrm{J}$ & 9.5100 & 0.4664 & 0.8869 & 0.8582 \\
\hline $\mathrm{B}$ & 11.4200 & 0.5395 & 0.9186 & 0.8953 \\
\hline F & 11.5800 & 0.5333 & 0.9046 & 0.8806 \\
\hline SSR01 & 19.8044 & 0.6333 & 0.9548 & 0.9472 \\
\hline SSR02 & 16.8750 & 0.9222 & 0.9460 & 0.9375 \\
\hline SSR03 & 9.7708 & 0.1111 & 0.9027 & 0.8887 \\
\hline SSR05 & 8.9207 & 0.1667 & 0.8929 & 0.8780 \\
\hline SSR06 & 27.36749 & 0.7444 & 0.9688 & 0.9622 \\
\hline SSR07 & 11.8756 & 0.7640 & 0.9210 & 0.9099 \\
\hline SSR08 & 6.2069 & 0.1000 & 0.8436 & 0.8236 \\
\hline
\end{tabular}

\section{Transcriptome data analysis}

Transcriptome data analysis compared the clean reads with the mapped genomic sequence of $P$. sinensis PelSin v 1.0 (http://www.ensembl.org/Pelodiscus_sinensis/Info/ Annotation/) by Tophat $\mathrm{v} 2.0 .5$. There were $38,193,853$ reads (mapping rate $83.3 \%$ ) for $P$. sinensis Japanese strain (J), 38,654,927 reads (mapping rate 80.1\%) for Qingxi black turtle (B), and 40,784,302 reads (mapping rate $81.3 \%$ ) for hybrid $(\mathrm{H})$ aligned to mapped reads successfully. Among the successful reads, 69.8, 67.7, and $69.4 \%$ could align to uniquely mapped reads, respectively (Table 4).

Table 4. Transcriptome data for the Pelodiscus sinensis Japanese strain, the Qingxi black turtle, and their hybrid.

\begin{tabular}{l|c|c|c|c|c|c|c|c}
\hline Sample & Clean reads & Clean bases & Mapped reads & Mapping rate & Unique mapped reads & Unique mapped rate & Duplication mapped rate & Base mismatch rate \\
\hline $\mathrm{J}$ & 45861092 & 4631970292 & 38193853 & $83.3 \%$ & 26641286 & $69.8 \%$ & $30.2 \%$ & $0.3 \%$ \\
\hline $\mathrm{B}$ & 48277702 & 4876047902 & 38654927 & $80.1 \%$ & 26173303 & $67.7 \%$ & $32.3 \%$ & $0.4 \%$ \\
\hline $\mathrm{H}$ & 50154664 & 5065621064 & 40784302 & $81.3 \%$ & 28305678 & $69.4 \%$ & $30.6 \%$ & $0.4 \%$ \\
\hline
\end{tabular}

The three transcriptome data contained 73,161 transcripts and coding 19,172 genes, accounting for 93.6 and $99.2 \%$ in known transcripts and annotated genes of $P$. sinensis. The transcriptome of $P$. sinensis Japanese strain contained 67,761 transcripts and coding 18,187 genes; however, the Qingxi black turtle had 68,061 transcripts and coding 17,993 genes, and there were 68,276 transcripts and coding 18,036 genes in the hybrid turtle. Three transcriptomes

Genetics and Molecular Research 16 (3): gmr16039148 
were compared to each other, indicating dramatic differences in expression levels of 29,626 transcripts and coding 12,763 genes. The expression levels of most differentially expressed transcripts reached 4-64 times in different groups (Figure 7).

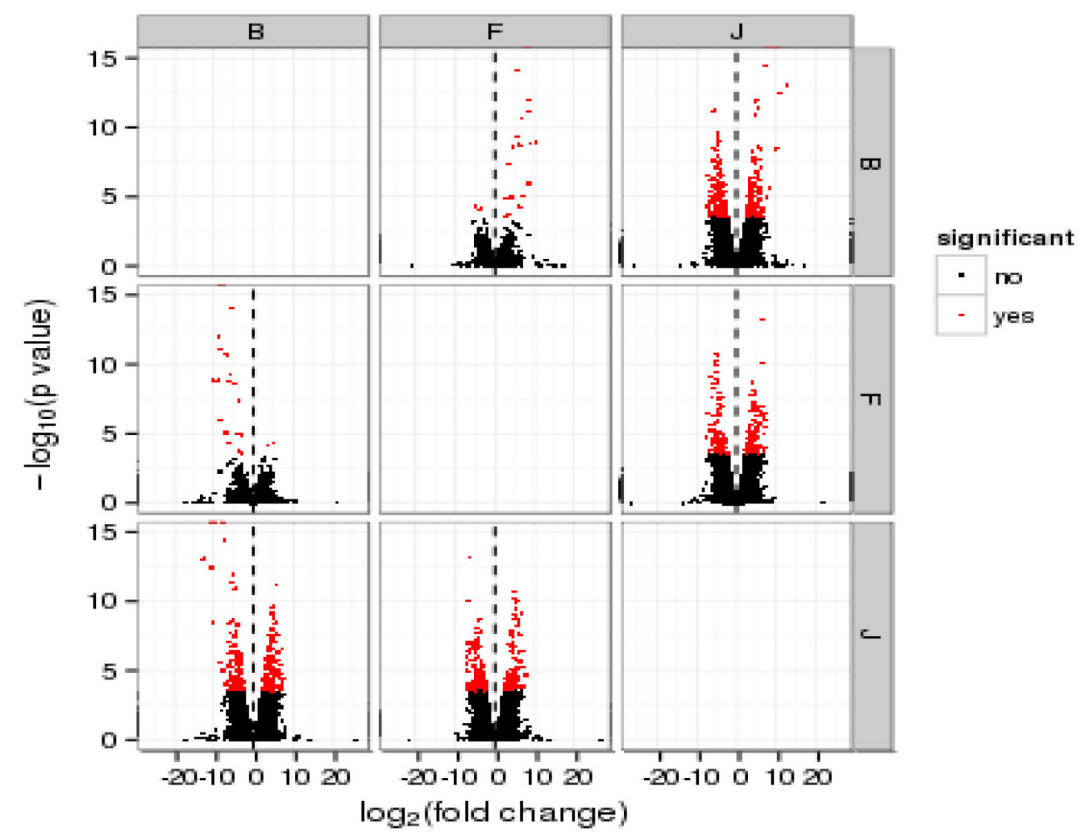

Figure 7. Pairwise comparisons of differentially expressed transcripts (red dots) for the Pelodiscus sinenses Japanese strain $(\mathrm{J})$, the Qingxi black turtle (B), and the hybrid turtle (F).

A total of 6975 transcripts were assigned to one or more GO terms. The most abundant GO biological process categories were "cellular processes" (GO: 0009987, 18.4\%), "metabolic processes" (GO: 0008152, 15.2\%), and "pigmentation" (GO: 004347, 13.8\%). In the molecular function category, "binding" (GO: 0005488, 42.2\%) and "catalytic activities" (GO: 0003824, 31.5\%) were the most abundant. In the cellular component category, "cell" (GO: 0005623, 29.8\%) and "cell part" (GO: 0043226, 30.1\%) represented the most abundant subcategories followed by "organelle" (GO: 0031090, 14.9\%). DEGs (1019) (FC $\geq 1$ ) were identified in 165 pathways with a KEGG pathway annotation; the first 20 pathways were listed in Table 5. The first three pathways with the most genes were pathways in cancer (ko05200, 28 genes), transcriptional misregulation in cancer (ko05202, 22 genes), and the Hippo signaling pathway (ko04390, 21 genes). We believed that these pathways were significant during the growth of the Chinese soft-shell turtle, in particular, metabolic pathways, which might be given a further research. Significant differentially expressed transcripts (274) were in the hybrid group compared to the two parental groups of the $P$. sinensis Japanese strain and the Qingxi black turtle. The expression pattern of different transcripts was classified according to Wang (2014) (Table 6). Among the differentially expressed genes, the expression pattern specific for the hybrid group included 114 genes compared to the $P$. sinensis Japanese strain. There were 7 differentially expressed genes indicating super-parent expression, and only 2 genes showing low-parent expression. 
Table 5. The first twenty KEGG pathways between the Pelodiscus sinensis Japanese strain, the Qingxi black turtle, and their hybrid.

\begin{tabular}{|c|c|c|c|c|c|c|c|c|}
\hline No. & KEGG & DGEs of $B$ and $J$ & No. & KEGG & DGEs of $\mathrm{F}$ and $\mathrm{J}$ & No. & KEGG & DGEs of $B$ and $F$ \\
\hline 1 & k005200: Pathways in cancer & 13 & 1 & ko05200: Pathways in cancer & 15 & 1 & ko05166: HTLV-I infection & 4 \\
\hline 2 & ko04390: Hippo signaling pathway & 11 & 2 & $\begin{array}{l}\text { k005202: Transcriptional misregulation } \\
\text { in cancer }\end{array}$ & 14 & 2 & $\begin{array}{l}\text { ko04261: Adrenergic signaling in } \\
\text { cardiomyocytes }\end{array}$ & 2 \\
\hline 3 & $\begin{array}{l}\text { ko04080: Neuroactive ligand-receptor } \\
\text { interaction }\end{array}$ & 10 & 3 & $\begin{array}{l}\text { ko04666: Fc gamma R-mediated } \\
\text { phagocytosis }\end{array}$ & 14 & 3 & ko04390: Hippo signaling pathway & 2 \\
\hline 4 & k004972: Pancreatic secretion & 9 & 4 & ko04146: Peroxisome & 12 & 4 & $\begin{array}{l}\text { ko04810: Regulation of actin } \\
\text { cytoskeleton }\end{array}$ & 2 \\
\hline 5 & ko00380: Tryptophan metabolism & 9 & 5 & ko05146: Amoebiasis & 11 & 5 & ko04024: cAMP signaling pathway & 2 \\
\hline 6 & $\begin{array}{l}\text { ko05202: Transcriptional misregulation } \\
\text { in cancer }\end{array}$ & 8 & 6 & ko00380: Tryptophan metabolism & 9 & 6 & ko05169: Epstein-Barr virus infection & 2 \\
\hline 7 & ko04915: Estrogen signaling pathway & 8 & 7 & ko04020: Calcium signaling pathway & 9 & 7 & ko04022: cGMP-PKG signaling pathway & 2 \\
\hline 8 & $\begin{array}{l}\text { ko00630: Glyoxylate and dicarboxylate } \\
\text { metabolism }\end{array}$ & 7 & 8 & \begin{tabular}{|l|}
$\begin{array}{l}\text { ko05322: Systemic lupus } \\
\text { erythematosus }\end{array}$ \\
\end{tabular} & 9 & 8 & ko05168: Herpes simplex infection & 2 \\
\hline 9 & k004068: FoxO signaling pathway & 7 & 9 & ko04390: Hippo signaling pathway & 8 & 9 & ko05034: Alcoholism & 2 \\
\hline 10 & ko04310: Wnt signaling pathway & 6 & 10 & ko04310: Wnt signaling pathway & 8 & 10 & ko05203: Viral carcinogenesis & 2 \\
\hline 11 & ko04146: Peroxisome & 6 & 11 & ko05210: Colorectal cancer & 8 & 11 & ko04510: Focal adhesion & 2 \\
\hline 12 & ko00410: beta-Alanine metabolism & 6 & 12 & ko01230: Biosynthesis of amino acids & 8 & 12 & ko04910: Insulin signaling pathway & 2 \\
\hline 13 & $\begin{array}{l}\text { ko04974: Protein digestion and } \\
\text { absorption }\end{array}$ & 6 & 13 & ko05323: Rheumatoid arthritis & 8 & 13 & k005205: Proteoglycans in cancer & 2 \\
\hline 14 & ko04024: cAMP signaling pathway & 6 & 14 & ko03320: PPAR signaling pathway & 8 & 14 & $\begin{array}{l}\text { k004974: Protein digestion and } \\
\text { absorption }\end{array}$ & 2 \\
\hline 15 & $\begin{array}{l}\text { ko05014: Amyotrophic lateral sclerosis } \\
\text { (ALS) }\end{array}$ & 6 & 15 & $\begin{array}{l}\text { ko04650: Natural killer cell mediated } \\
\text { cytotoxicity }\end{array}$ & 8 & 15 & ko03015: mRNA surveillance pathway & 2 \\
\hline 16 & ko05210: Colorectal cancer & 6 & 16 & $\begin{array}{l}\text { ko04664: Fc epsilon RI signaling } \\
\text { pathway }\end{array}$ & 8 & 16 & $\begin{array}{l}\begin{array}{l}\text { ko04270: Vascular smooth muscle } \\
\text { contraction }\end{array} \\
\end{array}$ & 2 \\
\hline 17 & k005213: Endometrial cancer & 6 & 17 & $\begin{array}{l}\text { ko04810: Regulation of actin } \\
\text { cytoskeleton }\end{array}$ & 7 & 17 & ko04611: Platelet activation & 2 \\
\hline 18 & $\begin{array}{l}\text { k004022: cGMP-PKG signaling } \\
\text { pathway }\end{array}$ & 6 & 18 & ko04068: FoxO signaling pathway & 7 & 18 & ko04921: Oxytocin signaling pathway & 2 \\
\hline 19 & $\begin{array}{l}\text { ko04550: Signaling pathways regulating } \\
\text { pluripotency of stem cells }\end{array}$ & 6 & 19 & $\begin{array}{l}\text { k000630: Glyoxylate and dicarboxylate } \\
\text { metabolism }\end{array}$ & 7 & 19 & $\begin{array}{l}\text { ko04750: Inflammatory mediator } \\
\text { regulation of TRP channels }\end{array}$ & 2 \\
\hline 20 & $\begin{array}{l}\text { ko04261: Adrenergic signaling in } \\
\text { cardiomyocytes }\end{array}$ & 6 & 20 & $\begin{array}{l}\text { ko00592: alpha-Linolenic acid } \\
\text { metabolism }\end{array}$ & 7 & 20 & ko03013: RNA transport & 2 \\
\hline
\end{tabular}

Table 6. Expression of differentially expressed transcripts in the hybrid turtle compared to the two parental.

\begin{tabular}{l|c|c|c|c|c|c}
\hline Item & $\begin{array}{c}\text { Super-parent } \\
\text { expression }\end{array}$ & $\begin{array}{c}\text { Low-parent } \\
\text { expression }\end{array}$ & $\begin{array}{c}\text { Specific expression } \\
\text { higher than female }\end{array}$ & $\begin{array}{c}\text { Specific expression } \\
\text { higher than male }\end{array}$ & $\begin{array}{c}\text { Specific expression } \\
\text { lower than female }\end{array}$ & $\begin{array}{c}\text { Specific expression } \\
\text { lower than male }\end{array}$ \\
\hline Number & 7 & 2 & 114 & 36 & 101 & 14 \\
\hline$(\%)$ & $(2.55)$ & $(0.73)$ & $(41.6)$ & $(13.1)$ & $(36.9)$ & $(5.11)$ \\
\hline
\end{tabular}

\section{DISCUSSION}

Morphology is one of the most natural and visible performances of biological, genetic variation, which can provide the basis for genetic improvement and breeding. The morphological characteristics of fish are mainly determined by genetic factors. However, at the same time, they had close relationships with their behavior, eating patterns, and living environment. The morphological analyses of hybrid and their parents are the most basic work in cross breeding and are also very necessary in the breeding work. The visible phenotypic differences can provide a theoretical basis for developing the few new varieties from further biochemical, molecular genetic analysis of parents, and offspring genetic variation. There was a significant difference between the Chinese soft-shelled turtle of Taihu population and the Japanese introduced population in shapes (Liu et al., 2013). The main differences of morphological characteristics between ecocultural and greenhouse cultural soft-shelled turtle were reported (Qian and Zhu, 2002). We screened the differences of morphological characteristics in $P$. sinensis Japanese strains, Qingxi black turtle, and their hybrids for comprehensive analysis of the domestic germplasm of $P$. sinensis. It could provide a basis for the further study of genetic differences in the local strain and strain breeding of $P$. sinensis.

Body color in domestic animals is one of the most strikingly variable and visible traits and has been widely used as a unique phenotype in the morphological selection for 
breed identification and attribution. The black soft-shelled turtle has been considered as a precious strain of soft-shelled turtle by consumers and well welcomed at the market at an even much higher price, and therefore, purifying the abdomen black character instead of growth performance, as usual, becomes the main breeding purpose. The breeding programs of Qingxi black turtle began in 1993, and the black abdomen feature was genetically stable after five successive generations by adopting the population selective breeding method (Zhang et al., 2008; Xue et al., 2009). As animal coloration is an ideal model for studying the genetic mechanisms that determine phenotype (Hubbard et al., 2010), the Qingxi black turtle has been an important breeding material, then preserving the turtle resources should be enhanced. Although the black abdomen feature has been found in the Qingxi black turtle and the differences between transcriptomes of three color turtles have been analyzed, its mechanism of melanin synthesis and accumulation are still unclear.

The growth rate was the main trait to evaluate the efficiency and economic value in aquaculture production. In this paper, two parental groups of $P$. sinensis Japanese strain and Qingxi black turtle and their hybrid were compared in the same pool by the individual fluorescent markers. The growth rate of the juvenile hybrid was faster than the $P$. sinensis Japanese strain and the Qingxi black turtle in the immature stage. The faster growth ratio of hybrid turtle obviously showed the super-parent phenomenon. Compared with parent self-bred progenies in growth rate, genetic diversity, and gene expression, hybrid had certain advantages in the growth and presented growth vigor. It was worth further genetic improving in the future.

For the genetic mechanism of heterosis, two or more individual genes from different species or strains with different genetic basis could combine freely through crossbreeding and the genetic constitution of hybrid progeny changed and adapted, then new genetic types appeared (Lippman and Zamir, 2007). The differences including the genotype and gene polymorphism existed between the parents were necessary for heterosis utilization (Hu et al., 1999). In this paper, the liver transcriptome analysis of the hybrid and two parents showed similar distribution abundance in the parental and hybrid groups, but the transcripts with high abundance appeared in the hybrid group. Among the 274 significant differentially expressed transcripts, 7 differentially expressed genes indicated super-parent expression, and 2 genes showed low-parent expression in the hybrid group compared to the two parental groups. The molecular markers of polymorphism mostly reflect the genetic polymorphisms of regulatory sequence rather than the coding region polymorphisms (Johns et al., 1983; Govindaraju and Cullis, 1992). The expression of regulatory genes was more flexible to adapt to the requirements of natural selection. Compared with the parents, the first generation of hybrids changed in many characters. These changes were related to the expression of genes in hybridization condition, obviously in the gene expression patterns or quantities. Moreover, the expression changes should be mainly contributed to regulatory region changes rather than coding region sequences. In this paper, $H_{\mathrm{E}}$ of the hybrid turtle was 0.9186 , which was higher than 0.9046 of the Qingxi black turtle and 0.8869 of the P. sinensis Japanese strain. Gene expression differences between hybrids and its parents were screened by transcriptome analysis. From the differentially expressed genes of $P$. sinensis Japanese strain, Qingxi black turtle, and their hybrid, various expression patterns such as super dominance, additive effect, and low dominance were revealed in the complex heterosis mechanism for $P$. sinensis. Therefore, the heterosis mechanism of $P$. sinensis remains further study deeply and provides new ways for genetic improvement of $P$. sinensis.

Genetics and Molecular Research 16 (3): gmr16039148 


\section{ACKNOWLEDGMENTS}

Research supported by a grant from the Major Special Program of Breeding of Zhejiang Province, China (\#2012C12907-1 and \#2016C02055-4).

\section{REFERENCES}

Aleherr S and Freyer D (2000). Asian turtles are threatened by extinction. Turt. Tortoise Newsl. 1: 7-11.

Ashburner M, Ball CA, Blake JA, Botstein D, et al.; The Gene Ontology Consortium (2000). Gene ontology: tool for the unification of biology. Nat. Genet. 25: 25-29. https://doi.org/10.1038/75556

Benjamini Y and Yekutieli D (2001). The control of the false discovery rate in multiple testing under dependency. Ann. Stat. 29: 1165-1188

Bonin F, Devaux B and Dupré A (2006). Turtles of the world. Transl. P.C.H. Pritchard. Johns Hopkins University Press, Baltimore.

Botstein D, White RL, Skolnick M and Davis RW (1980). Construction of a genetic linkage map in man using restriction fragment length polymorphisms. Am. J. Hum. Genet. 32: 314-331.

Bureau of Fisheries (2015). 2014 China fishery statistical yearbook. China Agriculture Press, Beijing.

Govindaraju D and Cullis C (1992). Ribosomal DNA variation among populations of a Pinusrigida Mill (Pitch Pine) ecosystem. 1. Distribution of copy numbers. Heredity 69: 133-140. https://doi.org/10.1038/hdy.1992.106

He ZY (2014). Discussion on construction and operation mechanism of the integrated system of breeding, propagation and extension of aquatic seed industry: Modern seed industry development of Pelodiscus sinensis, Higher Education Press, Beijing.

He ZY, Zhang HQ and Cai YW (2015). High-efficiency culture models strategy for soft-shelled turtle, China Agriculture Press, Beijing.

Hu JG, Yang JS and Chen JT (1999). Genetic basis of crops heterosis. Hereditas 21: 47-50.

Hubbard JK, Uy JA, Hauber ME, Hoekstra HE, et al. (2010). Vertebrate pigmentation: from underlying genes to adaptive function. Trends Genet. 26: 231-239. https://doi.org/10.1016/j.tig.2010.02.002

Johns MA, Strommer JN and Freeling M (1983). Exceptionally high levels of restriction site polymorphism in DNA near the maize Adh1 gene. Genetics 105: 733-743.

Kanehisa M, Goto S, Sato Y, Furumichi M, et al. (2012). KEGG for integration and interpretation of large-scale molecular data sets. Nucleic Acids Res. 40: D109-D114. https://doi.org/10.1093/nar/gkr988

Jia YD (2007). Different breed or strain Trionyx sinensis hybridization tests research and the Trionyx sinensis immunity respondent to LPS. Master degree dissertation of Huazhong Agricultural University, Wuhan, China, 10-16.

Lippman ZB and Zamir D (2007). Heterosis: revisiting the magic. Trends Genet. 23: 60-66. https://doi.org/10.1016/j. tig.2006.12.006

Liu Y, Long J J, Liu J Y, et al. (2012). Comparative research on the growth of three populations of Trionyx sinensis in juvenile stage. Guangdong Agri. Sci. 14: 156-160.

Liu Y, Zhao J, Zhu XP, et al. (2013). Morphological analysis of five populations of soft shell turtle Trionyx sinensis. J Dalin Ocean University 28: 174-178.

Meng Q H, Xu X J, Zhang H Q, et al. (2013). Microsatellite DNA Analysis of soft-shelled turtle hybrid and its parents. $J$. Zhejiang Agric. Sci. 9: 1194-1197.

Mortazavi A, Williams BA, McCue K, Schaeffer L, et al. (2008). Mapping and quantifying mammalian transcriptomes by RNA-Seq. Nat. Methods 5: 621-628. https://doi.org/10.1038/nmeth.1226

Qian GY and Zhu QH (2002). The comparison of ecocultural soft-shelled turtle and greenhouse cultural soft-shelled turtle of features. Dongwuxue Zazhi 37: 52-54.

Que Y, Bin Z, Rosenthal H, et al. (2007). Isolation and characterization of microsatellites in Chinese soft-shelled turtle, Pelodiscus sinensis. Mol. Ecol. Notes 7: 1265-1267. https://doi.org/10.1111/j.1471-8286.2007.01850.x

Shao QJ (2013). Soft-shelled turtles. Aquaculture (second edition), Blackwell Publishing Ltd., Oxford, 460-475.

Shen Z G., Chen D F. Zhou R.Q. et al.(2011). National standards of technical specifications for pond Chinese soft-shelled turtle. Standards Press of China, Beijing, GB/T26876-2011.

Shi J and Li QL (2005). Application of cross hybrid in breeding of fine soft-shelled turtle. Freshwater Fisheries 35: 38-39.

Trapnell C, Pachter L and Salzberg SL (2009). TopHat: discovering splice junctions with RNA-Seq. Bioinformatics 25: 1105-1111. https://doi.org/10.1093/bioinformatics/btp120

Wang H (2014). Gene expression in fat body and its correlation to heterosis in silkworm reciprocal hybrids based on digital

Genetics and Molecular Research 16 (3): gmr16039148 
gene expression profile. Master Degree Dissertation of Soochow University, 23-24.

Wang W, Li CY, Ge CT, Lei L, et al. (2013). De-novo characterization of the soft-shelled turtle Pelodiscus sinensis transcriptome using Illumina RNA-Seq technology. J. Zhejiang Univ. Sci. B 14: 58-67. https://doi.org/10.1631/jzus. B1200219

Wang Z H, Wang C S, Qian G Y (2009). Preliminary study on growth and nutritional traits of hybrids offspring of Pelodiscus sinensis. Jiangsu Agri. Sci. 5: 221-223.

Wu ZL and Zeng XQ (2007). Culture Vision of turtle and tortoise in China, China Agriculture Press, Beijing.

Xu XJ, Du JM, Zhang HQ, et al. (2012). Study on fluorescent tagging of juvenile soft-shelled turtle (Pelodiscus sinensis). J. Ningbo Univ 25: 13-16.

Xue H L, He Z Y, Zhang H Q, et al. (2009). Preliminary research on culture performance of Qingxi black turtle, Chin. Fisher. 6: 42-43.

Zhang C, Xu XJ, Zhang HQ, Mu CK, et al. (2015a). PCR-RFLP identification of four Chinese soft-shelled turtle Pelodiscus sinensis strains using mitochondrial genes. Mitochondrial DNA 26: 538-543. https://doi.org/10.3109/19401736.20 13.869674

Zhang H.Q.,He Z.Y., Xu X.L.,2008. Research on nutrients of Qingxi black turtle. China Fisheries 6: 76-79.

Zhang HQ, He ZY and Shao JZ (2011). Analysis and comparison of genetic diversity in the new cultured varieties of Pelodiscus sinensis. J. Economic Animal 15: 39-46.

Zhang HQ, He ZY and Yan YY (2012). Status and developing countermeasure of Pelodiscus sinensis Japanese strain. $J$. Zhejiang Agri. Sci. 5: 742-744.

Zhang HQ, Zhang C, Xu XJ, Zhu JJ, et al. (2015b). Differentiation of four strains of Chinese soft-shelled turtle (Pelodiscus sinensis) based on high-resolution melting analysis of single nucleotide polymorphism sites in mitochondrial DNA. Genet. Mol. Res. 14: 13144-13150. https://doi.org/10.4238/2015.October.26.10

Zhang M, Zong Y and Ma J (1998). Fauna Sinica: Reptilian, 1. Science Press, Beijing, China.

Zhang XJ, Liu Y and Zhou GJ (2007). National standards of Chinese soft-shelled turtle. Standards Press of China, Beijing, GB21044-2007.

Zhu LM, Li ZQ, Li JL, et al. (2012). Genetic Diversity of Farmed Chinese Soft-Shelled Turtle (Pelodiscus sinensis) evaluated from microsatellite analysis. J. Anim. Vet. Adv. 11: 1217-1222. https://doi.org/10.3923/javaa.2012.1217.1222

Genetics and Molecular Research 16 (3): gmr16039148 